\title{
Comparative structural Analysis of Acme and Square thread Screw jack using Autodesk Inventor
}

\author{
Mrs. Swati V. Borse \\ Student, \\ D.N.Patel College of Engineering \\ Shahada (M.S.), India \\ borseswati000@gmail.com
}

\author{
Dr. D.M. Patel \\ Associate Professor, \\ D.N.Patel College of Engineering \\ Shahada (M.S.), India \\ borseswati000@gmail.com
}

\begin{abstract}
A screw jack is a device used to lift the vehicle above the ground level in order to ease repairs. A power screw is designed to translate radial motion to linear motion. Many users are familiar with manually operated car jack which still included as standard equipment in cars. A car jack is an important device in vehicle to change flat tire in our journey. Every year near about 160 injuries are associated with car jacks. The correct use of jacks can prevent the accidents and injuries. Improvement in Design of car jack is really important to make the tool more efficient and user friendly with high safety features.

The objectives of this paper is to critically analyze and compare between ACME and SQUARE threads from stress and strain perspective in order to improve the performance from safety and durability point of view for developments in the field of thread design. In this paper selection of two different types of screw threads namely Square and Acme threads. The square threads are named after their square geometry. They are the most efficient power screw, but also the most difficult to machine, thus most expensive. The Acme threads are machining with multipoint cutting tool on thread milling machine, it is an economical operation. Acme threads have more thickness at core diameter than of Square threads therefore a screw with Acme threads is stronger than equivalent screw with Square threads.
\end{abstract}

Keywords-Screw jack, ACME thread, Square thread

$* * * * *$

\section{INTRODUCTION}

Power screw is an essential component of screw jack. It is a tool to lift and lower the load of materials / goods. There is a lot of research and developments have been done related to the improvement of the design of Power Screws as well as different types of thread analysis of screw jack. To enhance the performance of the power screw is required to modify screw jack components design and make it to reduce the effort requirement to operate screw jack equipment. Objective of design the Power screws is to minimize the amount of effort needed by the user to lifting and lowering mechanism.

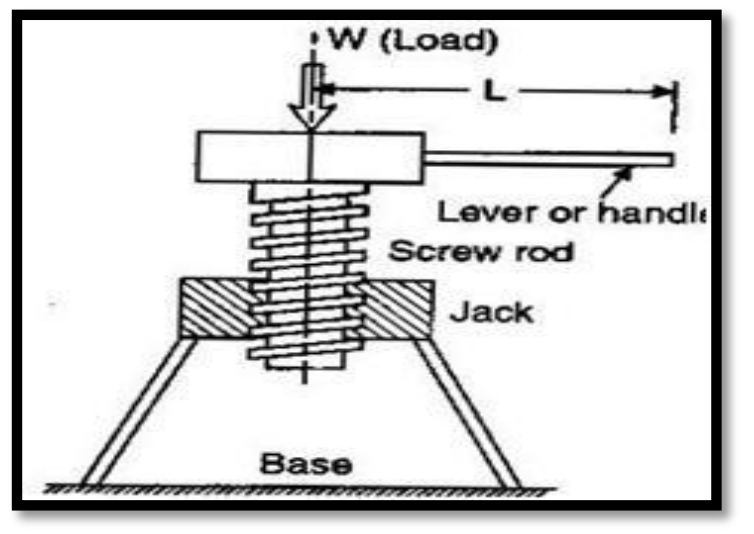

Figure 1: Simple Screw Jack

Screw jack is a mechanical device which is used to lift the load in applications of upward linear motion is required. To Lifting of any load, pushing or pulling of equipment. Specification of screw jack Mechanical capacity is vary from power screw is a component of screw jack and its important parameters are core diameter and helix angle of screw.

An advantage of screw jack over some other types of jack is that they are self-locking, which means when the rotational force on the screw is removed, it will remain motionless where it was left and will not rotate backwards, regardless of how much load it is supporting.

The most common application of screw jack is a car jack, floor jack or garage jack which lifts vehicles so that maintenance can be performed ergonomically. Car jacks usually use mechanical advantage to allow a human effort to lift a vehicle comfortably. More powerful jacks use in the heavy load lifting and larger distance movements loads. Mechanical jacks are usually rated for a maximum lifting capacity.

\section{PROBLEM STATEMENT}

The normal car jack available in market is operated manually. Manual operation required more Effort and time. Manual effort may lead to reduce the performance of load rising and lowering in the screw jack. Screw jack consists of cap, power screw, Tommy bar, cup etc., the performance of screw jack depends on power screw. In this paper we study the analysis of different paper to take this performance of screw jack focusing problem to study and it. Finally this paper 
concludes the improvement is required in the design and analysis of screw jack analysis papers.

To solve this problem, a research conducted on conventional type of screw jack to study and for solution on redesign of a car jack for the car by using simplest way along with energy saving.

\section{METHODOLOGY}

The performance of power screw investigation to carry out simulation technique and validated by manual calculations

\section{A. Simulation technique}

The scientific way of approaching the goals of this title is to study the existing different types of screw threads for car jack design, material and behavior towards the loading. Then the thread design and material change concept is to be applied. Various steel materials are to be compared on the basis of mechanical properties and their cost. Basically material strength and its factor of safety are the main selection criteria for materials.

Finite element analysis method is less expensive, quick and flexible than experimental methods hence it is to be carried out to predict the deformation and exact areas of deformation before laboratory testing.

\section{B. Modeling of screw jack (square threads)}

Solid modeling tool is available for developing idea and basic design of mechanical part and systems which can be analyses by use of FEA method.

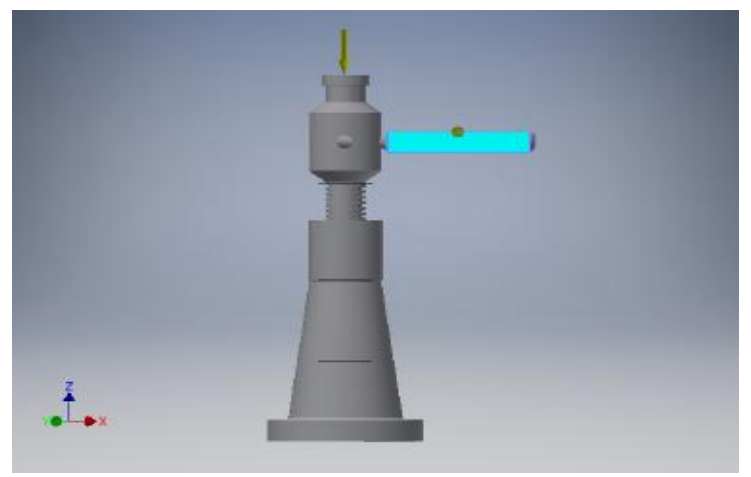

Figure 2: Modeling of square thread

C. Modeling of screw jack (acme threads)Solid modeling tool is available for developing idea and basic design of mechanical part and systems which can be analyses by use of FEA method. By use of above citied technique revives Occurrence of unnoticed Flaws can be minimized until phase of prototype stage.

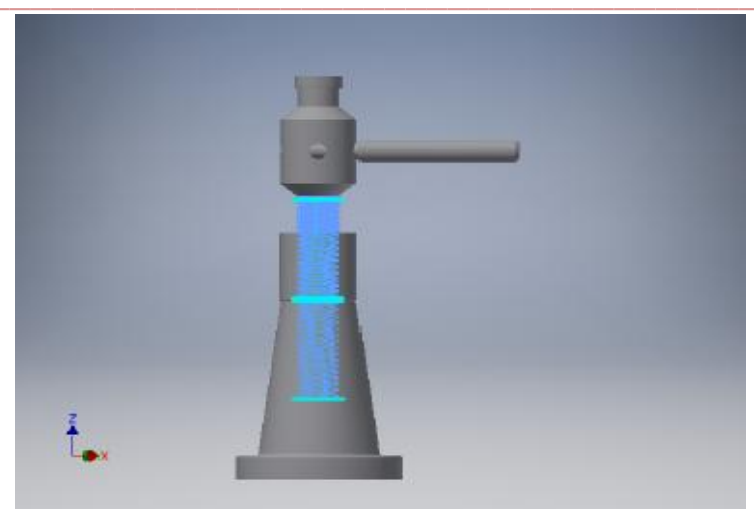

Figure 3: Modeling of Acme thread

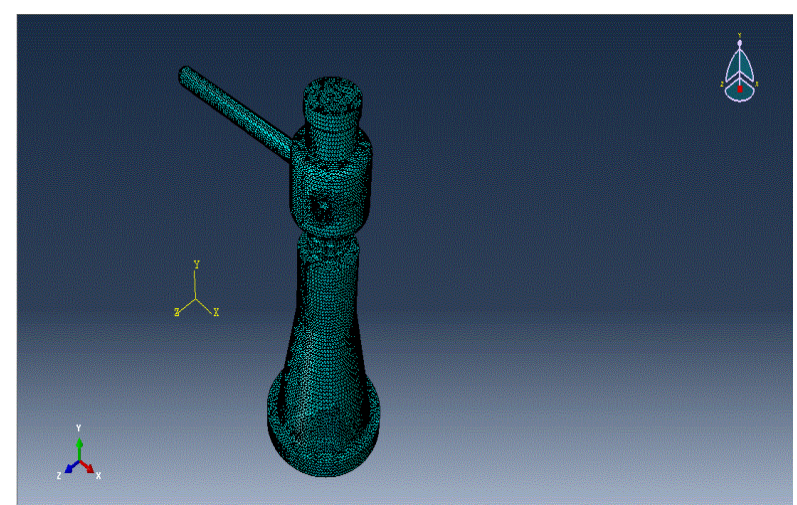

Figure 4: Meshed View- screw jack

Meshed model with connecting rod is shown in above Fig. with finite elements.

TABLE I

MATERIAL AND PROPERTIES

\begin{tabular}{|l|l|}
\hline Material selected & Alloy Steel \\
\hline Modulus of Elastisity,(E) & $207 \mathrm{MPa}$ \\
\hline Poisson's Ratio & 0.30 \\
\hline Tensile Ultimate strength & $621 \mathrm{MPa}$ \\
\hline Tensile Yield strength & $483 \mathrm{MPa}$ \\
\hline Density & Density $7700 \mathrm{~kg} / \mathrm{m} 3$ \\
\hline Shear modulus & $79 \mathrm{GPa}$ \\
\hline Behavior & \\
\hline
\end{tabular}

In this analysis modeled is analyzed under static condition case. In this case suitable loading and boundary condition applied on the screw jack and analysis is carried out.

\section{RESULTS AND DISCUSSION}

A. Result from Autodesk inventor software for Square thread: -Results of static analysis demonstrated via stresses, strain under effects of applied load..The FEA results for static analysis i.e. Von-Misses stress max. Principal stress, min. principal and Strain are shown in Fig. respectively. 


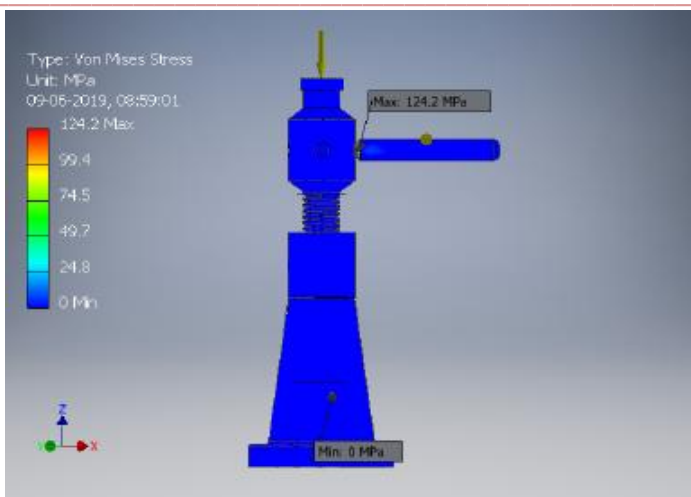

Figure 5: Finite Element Model of square thread screw jack Von mises Stres

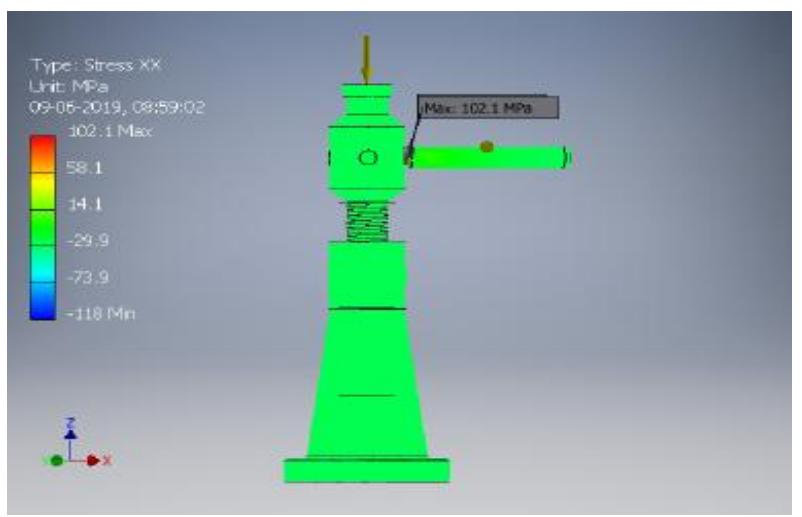

Figure 6: Finite Element Model of Square thread screw jack Stress along xx direction

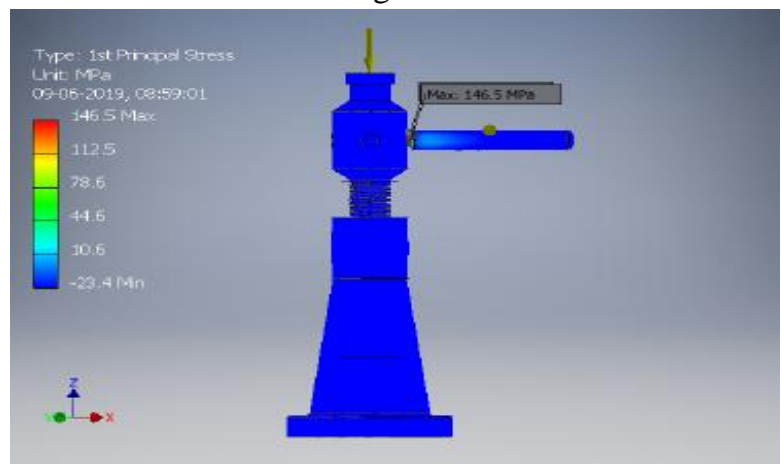

Figure 7: Finite Element Model of Square thread screw jack $1^{\text {st }}$ principle stress

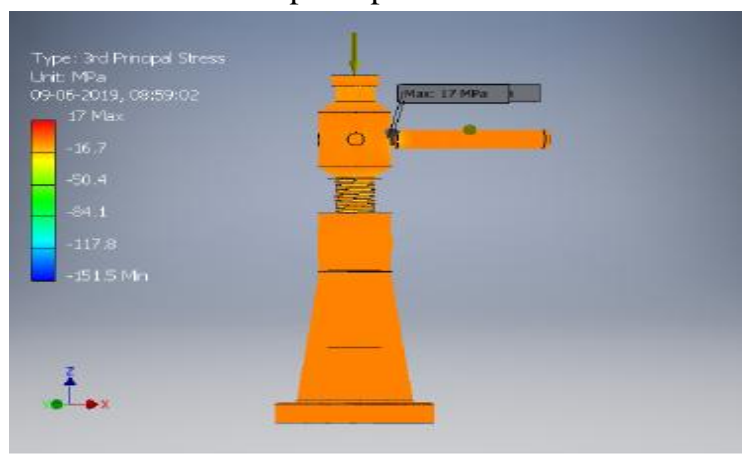

Figure 8: Finite Element Model of Square thread screw jack $3^{\text {rd }}$ principle stress

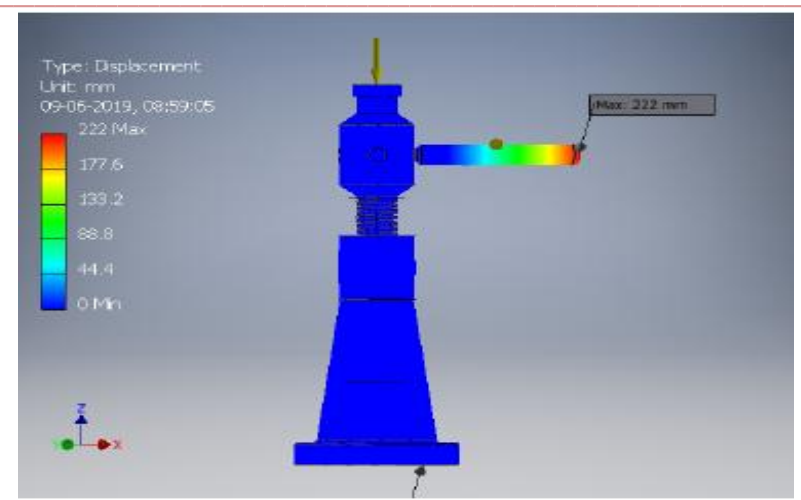

Figure 9: Finite Element Model of Square thread screw jack Max.Displacement

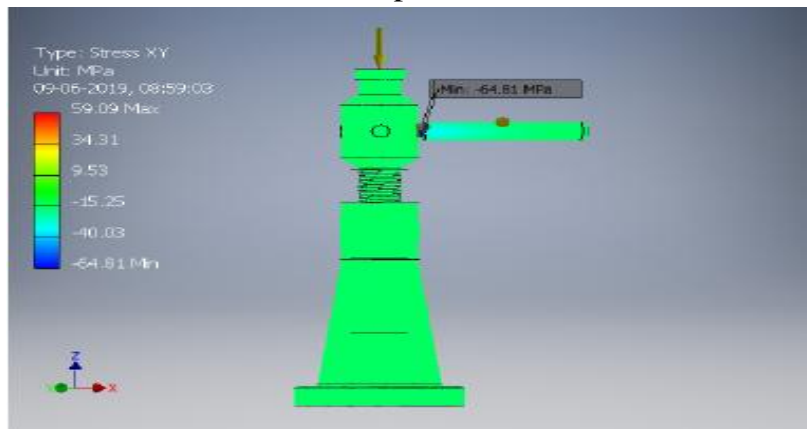

Figure 10: Finite Element Model of Square thread screw jack XY stress

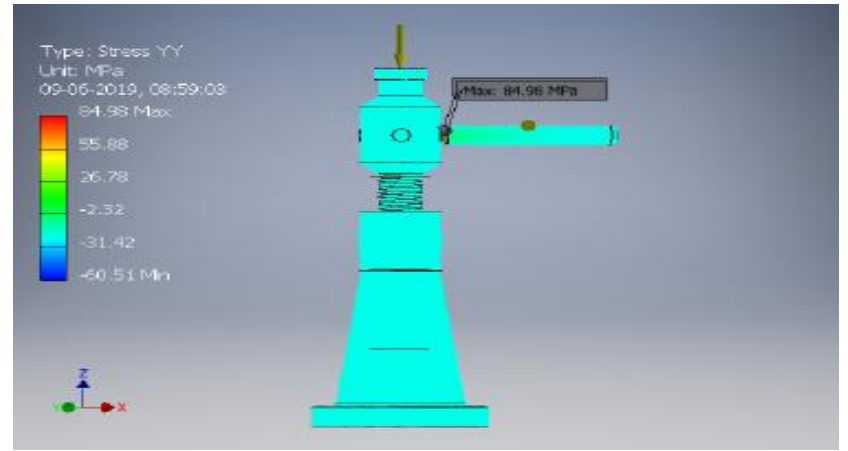

Figure 11: Finite Element Model of Square thread screw jack YY stress

B. Result from Autodesk inventor software for acme thread A. Results for Static Analysis:-Outputs of static analysis are shown via stresses, strain under the effects of applied load.

B. FEA results for static analysis that is Von-Misses stress max. Principal stress, min. principal and Strain are shown I Fig. below respectively.

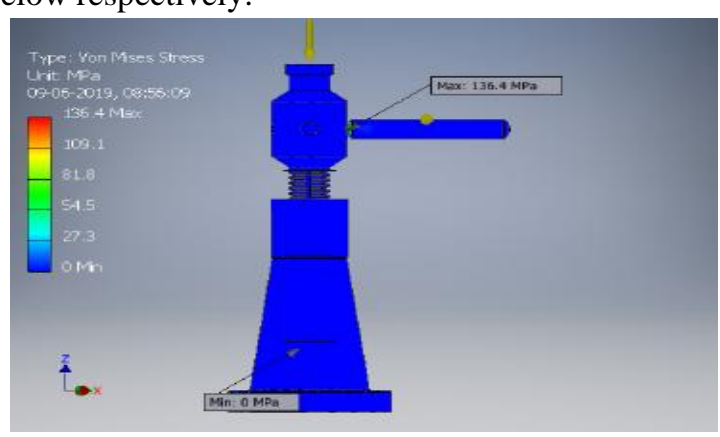

Figure 12: Finite Element Model of acme thread screw jack Von mises Stres 


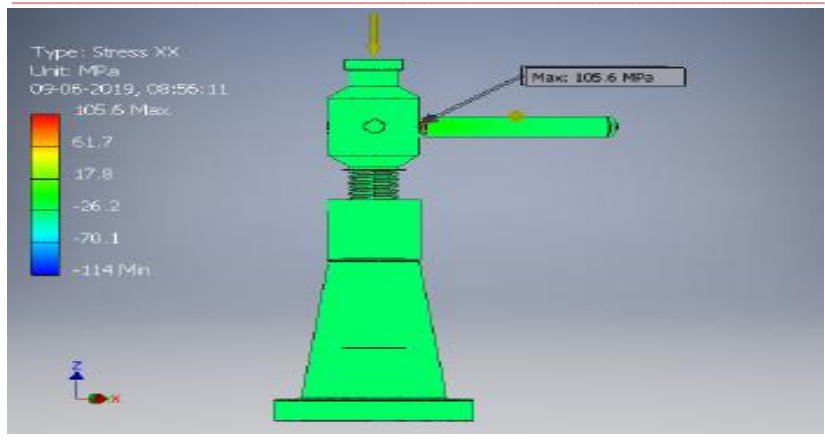

Figure 13: Finite Element Model of acme thread screw jack Stress along xx direction

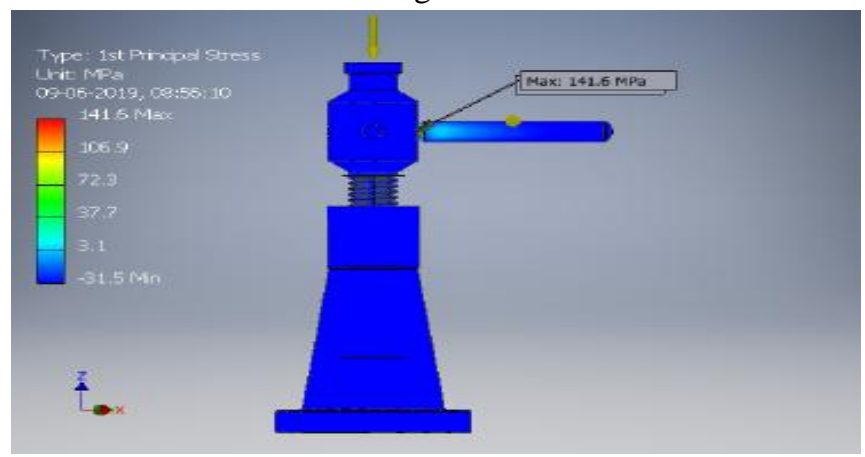

Figure 14: Finite Element Model of acme thread screw jack $1^{\text {st }}$ principle stress

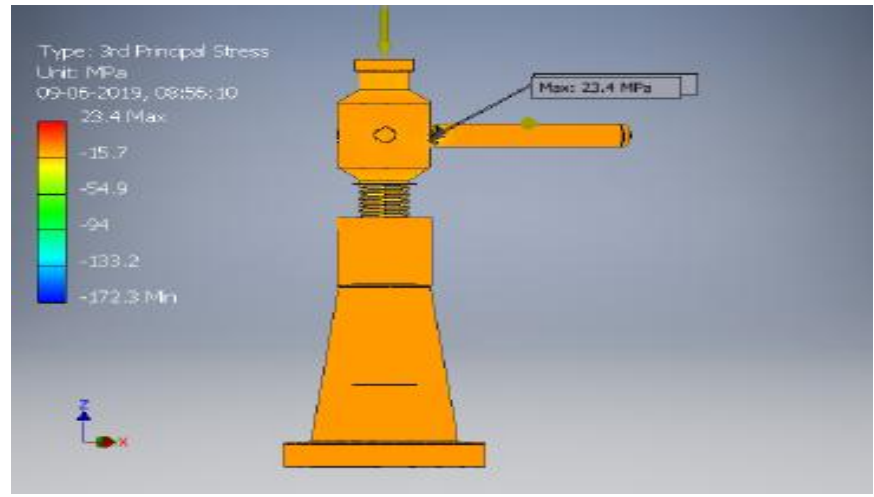

Figure 15: Finite Element Model of acme thread screw jack $3^{\text {rd }}$ principle stress

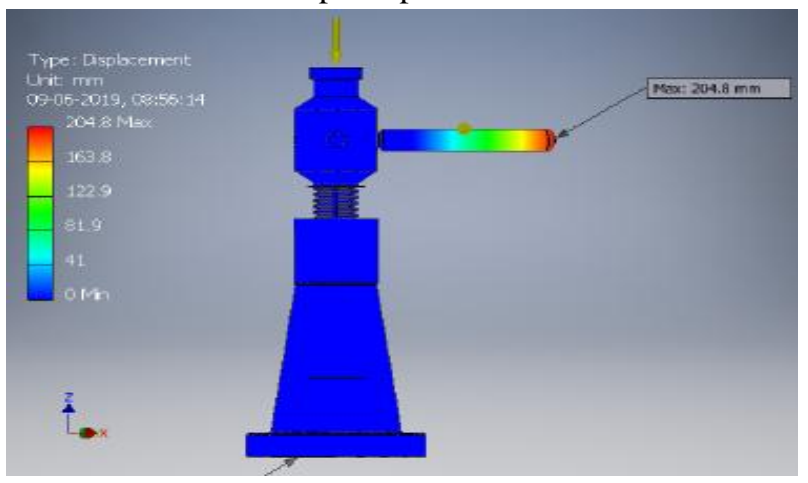

Figure 16: Finite Element Model of acme thread screw jackMax.Displacement

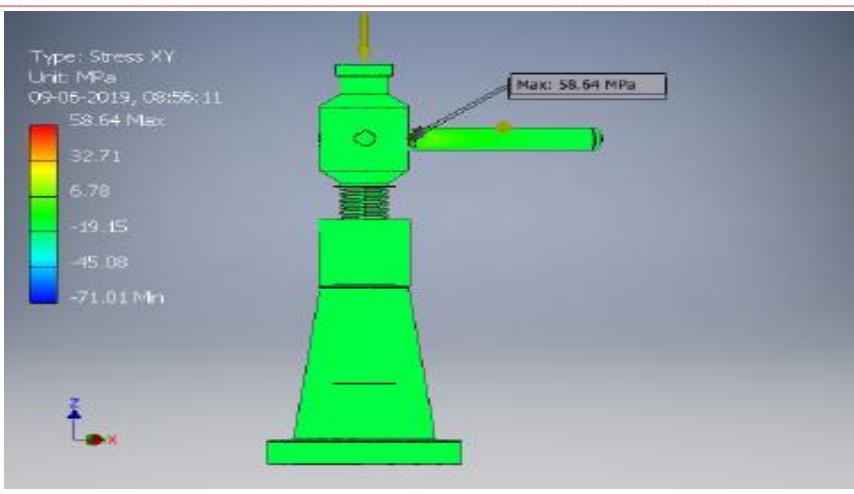

Figure 17: Finite Element Model of acme thread screw jack XY stress

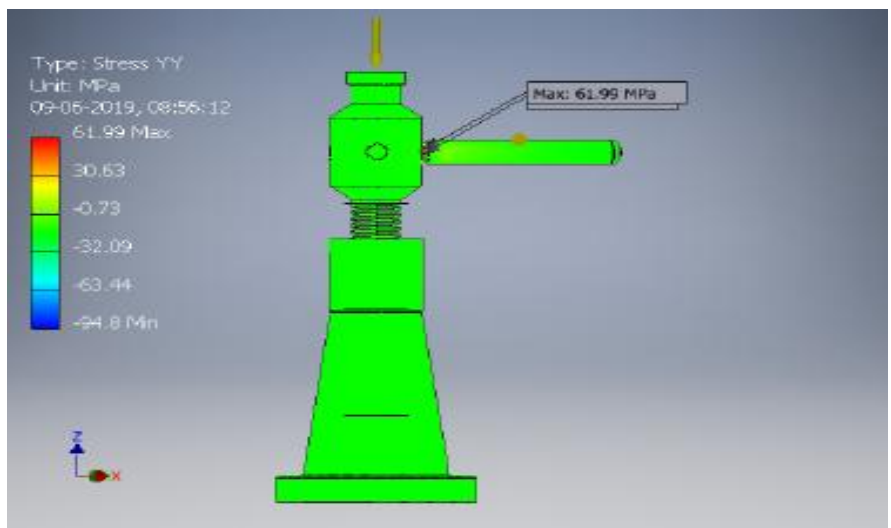

Figure 18: Finite Element Model of Square thread screw jack YY stress

\section{CONCLUSIONS}

Comparison of square and acme thread by different stress \& strain parameters

Table-II Comparison of square and acme thread

\begin{tabular}{|l|l|l|}
\hline Parameter & Square & Acme \\
\hline Von misses stress & $124.188 \mathrm{Mpa}$ & $136.367 \mathrm{Mpa}$ \\
\hline $\begin{array}{l}\text { Max. } \\
\text { Displacement }\end{array}$ & $222.017 \mathrm{~mm}$ & $204.785 \mathrm{~mm}$ \\
\hline Max. Principle & $146.507 \mathrm{Mpa}$ & $141.563 \mathrm{Mpa}$ \\
\hline Min Principle & $16.983 \mathrm{Mpa}$ & $23.477 \mathrm{Mpa}$ \\
\hline
\end{tabular}

From this comparisons we can deduce following conclusion

$>$ If more number of times we use screw jack then Acme thread is to be used though Max. von misses stress more for acme thread, for analysis is to be safe for fatigue point of view Acme threads are preferred

$>$ if fatigue is not a problem then square thread are recommended

$>$ on an average max displacement for square thread is always more than Acme thread for same load

$>$ If tolerance is not an issue and length is of no concern square thread should be recommended

$>$ Average minimum Principle stress for square thread is always less than that of Acme thread so stress fluctuation and positioning fluctuation are always more for square thread 
If we need same stress level square thread will be least weight as compared to acme thread hence design will be conservative of square thread which will be comfortable to ladies

$>$ Sudden failures chances of square thread are higher so in risky or corrosive environment square thread should not be recommended \& design modification required in future

\section{REFERENCES}

[1]. Thirugnanam et.al.(2014) "Analysis of Power Screw Using 'Ansys' Middle-East Journal of Scientific Research 20 (7), ISSN 1990-9233, IDOSI Publications, (2014), 868-870.

[2]. Manoj R Patil and S D Kachave (2015) "DESIGN AND ANALYSIS OF SCISSOR JACK"International Journal of Mechanical Engineering and Robotics Research India. ISSN 2278 - 0149 Vol. 4, No.1, January 2015 () 2015 IJMERR.

[3]. Egwero Oghenekome,Oladimeji Tolulolope(2014) "Design and implementation of remote controlled car jack Science Q journal vo-1, Issue 1.

[4]. Gaurav Shashikant Udgirkar et.al. (2014) "Design, Development and analysis of electrically operated toggle jack using power of car battery" ISSN (e): 2250 - 3005 || Vol, 04 || Issue, 7 || July - 2014 || International Journal of Computational Engineering Research (IJCER)

[5]. Sonu Yadav (2014) IJSRD - International Journal for Scientific Research \& Development| Vol. 2, Issue 10, 2014 | ISSN (online): 2321-0613

[6]. Prashant Kumar Srivastav, et al (2014),-Highly efficient motorized screw jackl, -International Journal of Computational Engineering Research\| Vol,03,Issue 5,pp 35-41

[7]. Prof. Nitinchandra R. Patel et.al. (2013), "Design Of Toggle Jack Considering Material Selection Of Scerw Nutcombination" International Journal of Innovative Research in Science, Engineering and Technology Vol. 2, Issue 5, (2013).

[8]. Tarachand G. Lokhande et.al. (2012) "Optimizing Efficiency of Square Threaded Mechanical Screw Jack by Varying Helix Angle" International Journal of Modern Engineering Research (IJMER) www.ijmer.com Vol.2, Issue.1, Jan-Feb 2012 pp-504508 ISSN: 2249-6645

[9]. Pandya J Milan ,Bhatt jaydeep(2005) journal of information, knowledge and research inmechanical engineeringissn $0975-$ $668 \mathrm{x} \mid$ nov 12 to oct 13 | volume -02 , issue - 02

[10].M.M. Noor et.al (2010) "Analysis Of Auto Car Jack", National Conference in Mechanical Engineering Research and Postgraduate Students 26-27 may 2010, FKM Conference Hall, UMP, Kuantan, Pahang, Malaysia, (2010) , 198-203. 